\title{
A rare case of non-surgical vocal cord paralysis: Vocal cord hematoma
}

\author{
Akif Enes Arıkan', Serkan Teksöz1', İsmail Ahmet Bilgin'1, Özge Tarhan², Ateș Özyeğin¹
}

\section{ABSTRACT}

\section{Cite this paper as:} Arıkan AE, Teksöz S, Bilgin IA, Tarhan 0̈, Özyeğin A. A rare case of non-surgical vocal cord paralysis: Vocal cord hematoma. Turk J Surg 2017; 33: 305-307.

'Department of General Surgery, İstanbul University Cerrahpaşa School of Medicine, İstanbul, Turkey

${ }^{2}$ Department of Ear, Nose and Throat, İstanbul University Cerrahpaşa School of Medicine, Istanbul, Turkey

\section{Address for Correspondence Akif Enes Arikan} e-mail: enesarikan@yahoo.com

Received: 25.12.2014 Accepted: 28.03.2015 Available Online Date: 14.07.2015

\section{oCopyright 2017} by Turkish Surgical Association Available online at www.turkjsurg.com
Although vocal cord paralysis (VCP) following thyroidectomy is primarily associated with surgical trauma, it is not the sole etiology. Vocal cord paralysis following thyroidectomy can be caused by a vocal cord hematoma with an incidence of $1.4 \%$ due to direct injury during orotracheal intubation. In this article, we present a case of VCP caused by vocal cord hematoma. A 32-year-old male patient who has been receiving propylthiouracil treatment for toxic multinodular goiter since 10 years was admitted to our hospital to be operated because of persisting complaints. The patient was hospitalized for sutureless thyroidectomy after he became euthyroid. Preoperative fiberoptic laryngoscopy performed by the ear, nose, and throat department revealed bilaterally motile vocal folds and a completely open airway. Patient underwent sutureless total thyroidectomy with a vessel sealing device (Ligasure ${ }^{\mathrm{TM}}$ LF1212, Covidien, $\mathrm{CO}$ ), and a minivac drainage system was placed in the thyroid lodge. On the morning of the first postoperative day, $50 \mathrm{~mL}$ of serosanguinous fluid was drained. The patient's voice was normal, and there was no ecchymosis. Postoperative fiberoptic laryngoscopy revealed a hematoma near the right vocal fold and paralysis of the right vocal fold; however, the airway was open. It should be kept in mind that VCP is not solely due to surgery but can also result from intubation, as observed in this case.

Keywords: Vocal cord hematoma, vocal cord paralysis, hematoma, thyroidectomy

\section{INTRODUCTION}

Thyroid surgery is one of the most popular surgeries worldwide. Postoperative hematoma after total thyroidectomy is a major but unpredictable complication. However, it can be diagnosed by follow-up after surgery even in unsuspected cases. Although it is generally asymptomatic, patients with postoperative hematoma can suffer from a range of symptoms from ecchymosis to life-threating dyspnea $(1,2)$.

Vocal cord paralysis (VCP) following thyroidectomy is another major complication, and its incidence has been varied $(1,2)$. Although VCP following thyroidectomy is primarily associated with surgical trauma, it is not the sole etiology. Vocal cord paralysis can result from nerve damage, such as transection (complete or partial), excessive traction, direct handling, contusion, crush, thermal injury, clamping, incorrect ligature, and compromised blood supply. In addition, neurological diseases, tuberculosis, aortic aneurysms, lung and mediastinal malignancies, esophageal malignancies, metastatic tumors, and post-anesthesia complications can cause VCP (1, 2). According to a review by Jeannon et al. (3) that includes 27 articles and evaluates over 25,000 patients, the average rate of temporary VCP is $9.8 \%(1.4 \%-38.4 \%)$, whereas the average rate of permanent VCP is $2.3 \%(0 \%-$ $18.6 \%)$. Vocal cord paralysis following thyroidectomy can result from a vocal cord hematoma with an incidence of $1.4 \%$, due to direct injury during orotracheal intubation (incidence: $4.5 \%)(4,5)$. In this article, a case with VCP resulting from vocal cord hematoma is presented.

\section{CASE PRESENTATION}

A 32-year-old male patient who has been receiving propylthiouracil treatment for toxic multinodular goiter since 10 years was admitted to our hospital because of persisting complaints of restlessness, fatigue, tremor, and heat intolerance. He was hospitalized for sutureless thyroidectomy after he became euthyroid. Preoperative fiberoptic laryngoscopy performed by the ear, nose, and throat department revealed bilaterally mobile vocal folds and a completely open airway. The patient underwent sutureless total thyroidectomy with a vessel sealing device (Ligasure ${ }^{\mathrm{TM}}$ LF1212, Covidien, CO) and a minivac drainage system was placed in the thyroid lodge (6). During operation, there was no loss of signal by intraoperative nerve monitoring (NIM-Response 3.0, Medtronic, FL). On the morning of the first postoperative day, $50 \mathrm{~mL}$ of serosanguinous fluid was drained. The drain was removed; his voice was normal and there were no ecchymosis. Postoperative fiberoptic laryngoscopy revealed a hematoma near the right vocal fold (Figure 1) and paralysis on the right vocal fold; however, the airway was open. The patient was discharged within $24 \mathrm{~h}$ after surgery. As a routine procedure, the patient was called for a follow-up on the tenth postoperative 


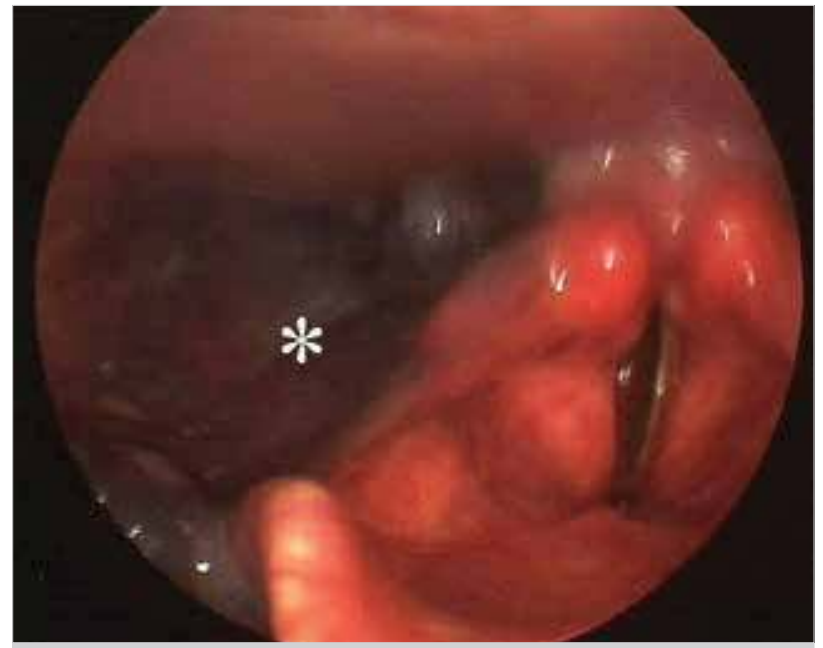

Figure 1. Early postoperative image of vocal folds.

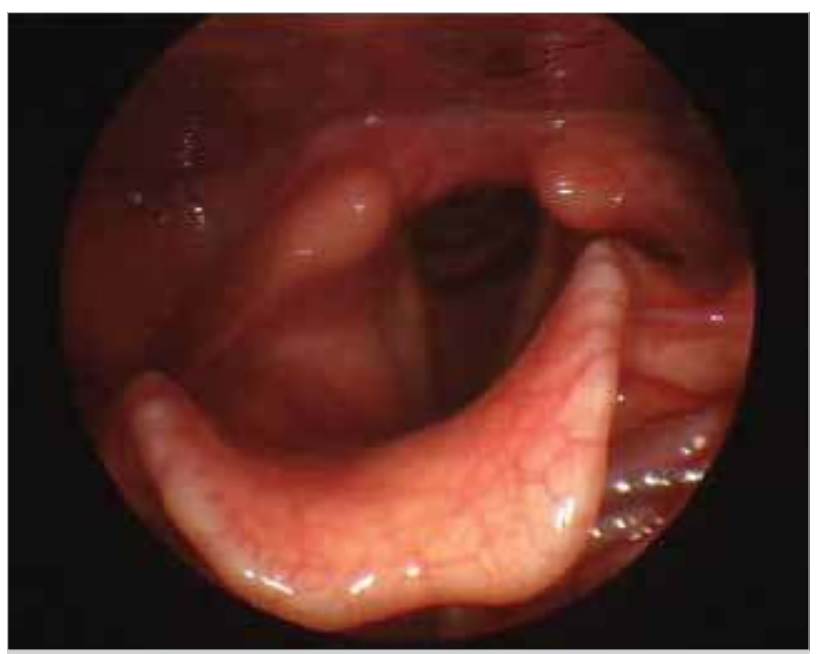

Figure 2. Sixth postoperative week image of vocal folds revealing that the previous hematoma on the right vocal fold had degraded.

day and at the sixth week, with the advice of application to the emergency department in case of any respiratory problems.

The patient did not apply to the emergency department or our clinic before the sixth postoperative week. Fiberoptic laryngoscopy on the sixth postoperative week revealed degraded hematoma and bilaterally mobile vocal folds (Figure 2). The same ear, nose, and throat doctor performed all fiberoptic laryngoscopies.

\section{DISCUSSION}

Unilateral vocal cord palsy (UVCP) is a complication of thyroidectomy; however, it is not solely caused by recurrent laryngeal nerve injury. According to a study by Spataro et al. (7), UVCP occurs in $46.3 \%-55.6 \%$ of patients. Regarding postoperative UVCPs, $14.9 \%-15.7 \%$ of all cases are due to thyroid surgery and $1.9 \%$ are due to parathyroid surgery. While malignancy is responsible for $17.8 \%-18.4 \%$ of UVCPs, direct invasion of thyroid cancer is responsible for $1.5 \%$. Of all UVCPs, $5.8 \%-6.2 \%$ are due to intubation, $3.2 \%-6.1 \%$ are due to trauma, and $13.2 \%-18.5 \%$ are idiopathic $(7,8)$. In this case, there was no nerve injury causing VCP; however, a hematoma caused dur- ing intubation resulted in VCP. Fifty percent of UVCPs are asymptomatic, as seen in this patient (9).

Vocal cord hematoma generally appears on the left vocal fold; this is typically related to right-sided insertion of the orotracheal tube and left-handed hold of the laryngoscope (10). However, this patient presented with a hematoma on the right side. The possible reasons for the right vocal fold injury are left handedness, inexperience, and prolonged intubation (4). Reasons for right-sided VCP in this case were not revealed even after discussing the case with the anesthesiology team.

It is hard to predict the development of a hematoma after surgery (11). Hematomas are the most limiting complications of short-stay thyroidectomy; however, this patient was discharged within $24 \mathrm{~h}$ after surgery.

\section{CONCLUSION}

It should be kept in mind that VCP does not solely result from surgery but can also result from intubation, as seen in this case.

Informed Consent: Written informed consent was obtained from patient who participated in this case.

Peer-review: Externally peer-reviewed.

Author Contributions: Concept - S.T., I.A.B.; Design - A.E.A., S.T.; Supervision - S.T., A.Ö.; Funding - A.E.A., S.T., I.A.B., Ö.T., A.Ö.; Materials - Ö.T., S.T., A.Ö.; Data Collection and/or Processing - A.E.A., S.T., I.A.B., Ö.T., A.Ö.; Analysis and/or Interpretation - A.E.A., S.T., I.A.B., Ö.T., A.Ö.; Literature Review - A.E.A., S.T.; Writer - A.E.A., S.T.; Critical Review A.E.A., S.T.

Conflict of Interest: No conflict of interest was declared by the authors.

Financial Disclosure: The authors declared that this study has received no financial support.

\section{REFERENCES}

1. Steurer M, Passler C, Denk DM, Schneider B, Niederle B, Bigenzahn W. Advantages of recurrent laryngeal nerve identification in thyroidectomy and parathyroidectomy and the importance of preoperative and postoperative laryngoscopic examination in more than 1000 nerves at risk. Laryngoscope 2002; 112: 124-133. [CrossRef]

2. Takano S, Nito T, Tamaruya N, Kimura M, Tayama N. Single institutional analysis of trends over 45 years in etiology of vocal fold paralysis. Auris Nasus Larynx 2012; 39: 597-600. [CrossRef]

3. Jeannon JP, Orabi AA, Bruch GA, Abdalsalam HA, Simo R. Diagnosis of recurrent laryngeal nerve palsy after thyroidectomy: $A$ systematic review. Int J Clin Pract 2009; 63: 624-629. [CrossRef]

4. Friedrich T, Hansch U, Eichfeld U, Steinert M, Staemmler A, Schonfelder M. Recurrent laryngeal nerve paralysis as intubation injury. Chirurg 2000; 71: 539-544. [CrossRef]

5. Kambic V, Radsel Z. Intubation lesions of the larynx. Br J Anaesth 1978; 50: 587-590. [CrossRef]

6. Arikan AE, Teksoz S, Bukey Y, Ferahman S, Ozcan M, Ozgultekin $\mathrm{R}$, et al. Short-stay sutureless thyroidectomy is safe and effective: Cerrahpasa experience. Surg Technol Int 2014; 25: 907-101.

7. Spataro EA, Grindler DJ, Paniello RC. Etiology and time to presentation of unilateral vocal fold paralysis. Otolaryngol Head Neck Surg 2014; 151: 286-293. [CrossRef] 
8. Rosenthal LH, Benninger MS, Deeb RH. Vocal fold immobility: A longitudinal analysis of etiology over 20 years. Laryngoscope 2007; 117: 1864-1870. [CrossRef]

9. Soylu L, Ozbas S, Uslu HY, Kocak S. The evaluation of the causes of subjective voice disturbances after thyroid surgery. Am J Surg 2007; 194: 317-322. [CrossRef]
10. Mencke T, Echternach M, Kleinschmidt S, Lux P, Barth V, Plinkert PK, et al. Laryngeal morbidity and quality of tracheal intubation: A randomized controlled trial. Anesthesiology 2003; 98: 1049-1056. [CrossRef]

11. Calo PG, Pisano G, Piga G, Medas F, Tatti A, Donati M, et al. Postoperative hematomas after thyroid surgery. Incidence and risk factors in our experience. Ann Ital Chir 2010; 81: 343-347. 